\title{
Life-threatening visceral complications after intragastric balloon insertion: Is the device, the patient or the doctor to blame?
}

\section{(ㄷ)(i)}

\author{
Authors \\ George Stavrou ${ }^{1,2}$, Georgia Tsaousi ${ }^{1}$, Katerina Kotzampassi ${ }^{1}$
}

Institutions

1 Department of Surgery, Aristotle University of Thessaloniki, Thessaloniki, Greece

2 Department of General Surgery, York Teaching Hospital, NHS Foundation Trust, York, UK

submitted 24.7.2018

accepted after revision 26.10.2018

\author{
Bibliography \\ DOI https://doi.org/10.1055/a-0809-4994 | \\ Endoscopy International Open 2019; 07: E122-E129 \\ (c) Georg Thieme Verlag KG Stuttgart · New York \\ ISSN 2364-3722
}

Corresponding author

Katerina Kotzampassi, MD, PhD, Department of Surgery, Aristotle University of Thessaloniki, AHEPA Hospital, 54006 Thessaloniki, Greece

Fax: +302313303496

kakothe@yahoo.com

\section{ABSTRACT}

Background and aim Intragastric balloon placement is established as a safe, relatively low-cost and well-tolerated minimally invasive procedure for weight loss, giving encouraging results under the strict prerequisite that the obese patient will enroll in a medically supervised weight loss program. This retrospective study reviews already published cases of severe visceral complications for the purpose of assigning responsibility to the device, the patient, or the doctor.

Methods We reviewed PubMed and Scopus archived publications describing intragastric balloon (BIB/Orbera)-related severe visceral complications, i.e. perforations and obstructions.

Results Twenty-two cases of gastric perforation, two cases of esophageal perforation and 10 cases of bowel obstruction were found. For the gastric perforation the endoscopist was responsible in nine cases, the patient in four, and the balloon itself in nine. For the two cases of esophageal perforation, the endoscopists were responsible, while for the 12 cases of bowel obstruction, the patient was responsible for seven and the device for the other five cases.

Conclusion BIB/Orbera balloon insertion remains a safe procedure, with a minimum of complications related to hollow viscera. Mandatory education and accreditation of physicians dealing with bariatric endoscopy and strict supervision of the obese individuals, while living with the balloon, will eliminate such complications.

\section{Introduction}

Use of an intragastric balloon (IGB), always under strictly determined indications, as an alternative, minimally invasive treatment for morbid obesity has a long history of early enthusiasm and late disappointment, successes and failures [1-8]. The most known and most frequently used IGB is the BIB (Bioenterics Intragastric Balloon), which was first made available in Europe in 1991. For the last few years, the same balloon has been available under the trade name ORBERA (Apollo Endosurgery Inc, Austin Texas, United States), having gained US Food and Drug Administration (FDA) approval for use in the United States in the summer of 2015.
Unexpectedly, a couple of psychiatrists [9] recommended that the device be withdrawn based on reports of adverse events posted on the FDA homepage and specifically because of four reports of "...patient death not definitively attributed to the device or the insertion procedure" and a further one "... related to potential complications associated with the balloon treatment". According to these, the safety both of ORBERA balloon and the Re-Shape is questionable, because based on their review [not cited] they have been implicated in a total of 27 deaths in the period between January 1, 2006 and October 5, 2017.

Motivated by this article, we decided to review the literature regarding complications related to the IGB, specifically those relating to visceral perforation or obstruction, leading to peri- 
tonitis, which required emergency surgery, which were sometimes followed by other complications and death. Our purpose was to find all publications referring to viscera-related complications in obese individuals in whom a BIB/Orbera balloon had been implanted and analyze how the procedure went wrong and, if possible, assign responsibility to the device, the patient or the doctor.

\section{Methods}

An electronic literature search of PubMed, Scopus, Cochrane Central Register of Controlled Trials, and International Web of Science databases from their inception to 2018 was performed to detect all published papers pertinent to the occurrence of serious complications like perforation (gastric or esophageal) and bowel obstruction following insertion of a BIB/ORBERA intragastric balloon for weight loss.

For literature search purposes, the subject heading "intragastric balloon" combined with the MESH terms "gastric perforation," "esophageal perforation", or "bowel obstruction" with "and" as Boolean term were applied to retrieve data related to the objectives of this study. A search of these terms was confined to the article title, abstract, and keywords of document search. Literature search was focused on human studies and full-length articles (no abstracts) with no language restriction. We aimed to single out all types of clinical studies such as randomized controlled trials (RCTs), prospective or retrospective observational studies and case reports relevant to insertion of intragastric balloon for weight loss.

The titles and abstracts of all studies identified were screened and assessed and those that were obviously irrelevant or duplicates were discarded. If eligibility could not be ascertained from the title or abstract, the full text of the study was retrieved and the papers deemed suitable were reviewed for eligibility according to their clinical relevance. References in the selected papers were scrutinized for additional articles in a further effort to ensure that relevant publications were not missed. An ultimate check of the databases was carried out on May 10, 2018.

The selected articles were thoroughly studied in order to be as precise as possible in assigning "responsibility" for the complications mentioned. This was based primarily on the comments of each author, who often was not the doctor who placed the balloon, but rather the surgeon who treated the complication, especially in cases of perforation. Our own personal judgement and experience in intragastric balloons was also taken into account.

\section{Results}

\section{Gastric perforation}

The research produced 16 articles [10-25] with 22 cases of gastric perforation: 13 case reports (14 cases) and three retrospective case series containing eight cases as follows: two cases out of 126 patients, one case out of 44 patients and five cases out of 2515 patients, respectively ( $\triangleright$ Table $\mathbf{1}$ ).

\section{Esophageal perforation}

Two case reports $[26,27]$ with one case each were identified ( Table 2).

\section{Bowel obstruction}

A total of 10 articles [8, 28-36] with 12 cases were found: seven case reports (7 cases) and three retrospective studies (5 cases) ( $\triangleright$ Table 3$)$.

\section{Discussion}

IGB placement has been established as a safe and well tolerated, minimally invasive procedure for morbid obesity management, by filling the gap between numerous conventional measures and bariatric surgery [7]. It has become popular in Europe, as well as in Brazil and Mexico, and only recently in the United States after FDA approval in 2015. It appears potentially effective, as many published results have revealed an average of between $55.6 \%$ and $32.1 \%$ loss of excess body weight at 6 months after treatment [ $2-4]$, or around $25 \%$ at 1 year $[3,6,7]$. In the majority of cases, this loss was maintained for a short or medium-term period, while $23 \%$ of patients maintained the loss for up to 5 years, in combination with diet, physical training, and lifestyle modification $[3,5,7]$. Due to the simplicity of the procedure, the encouraging results and the relative low cost of the device, there are hundreds of thousands of obese individuals who decide to follow this therapeutic option, either because they are not eligible for surgery, at high risk of complications from surgery, or simply afraid of it.

The Bioenterics intragastric balloon (Inamed Corporation, Santa Barbara, California, United States or Allergan, Irvine, California, United States), now marketed as Orbera (Apollo Endosurgery Inc, Austin, Texas, United States), is the device for which the most clinical experience and the most historical data supporting its use have been collected. It is the oldest such device in the market and complied with the fundamental requirements formulated for the optimal balloon design at the 1987 Tarpon Spring Conference $[1,37]$. According to the requirements, the balloon should be smooth, seamless, constructed of long-lasting material, have a low ulcerogenic potential, be adjustable for a variety of sizes, and should incorporate a radiopaque marker for proper identification in case of deflation.

It is also recommended that the balloon be left in place within the stomach for a maximum of 6 months while the patient is enrolled in a medically supervised weight loss program and receives proton pump inhibitors (PPIs) [3, 5, 15, 33]. In addition, balloon insertion should be carefully considered in cases of a large hiatus hernia, inflammatory bowel disease, increased risk of upper gastrointestinal bleeding, pregnancy, and uncontrolled psychiatric disease or drug/alcohol abuse [3]. Previous bariatric or gastric surgery is also considered a contraindication, although the absolute contraindication is reserved strictly for partial gastrectomy cases [38].

Insertion of the balloon under any of the above conditions could lead to increased risk of severe complications, with the possibility of fatal effects, i.e. gastric perforation, esophageal 


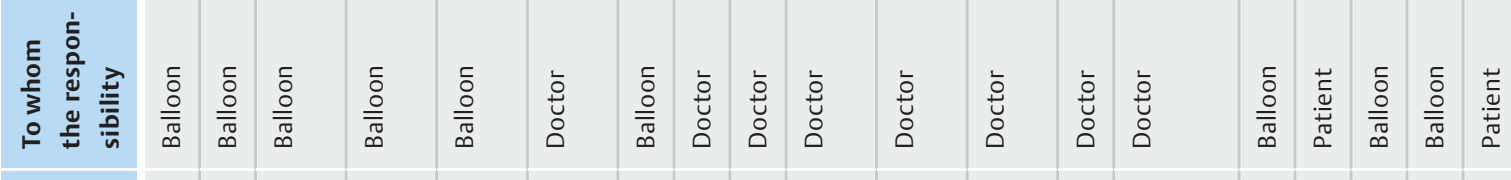

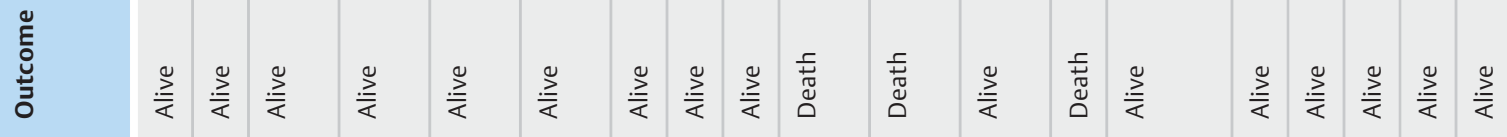

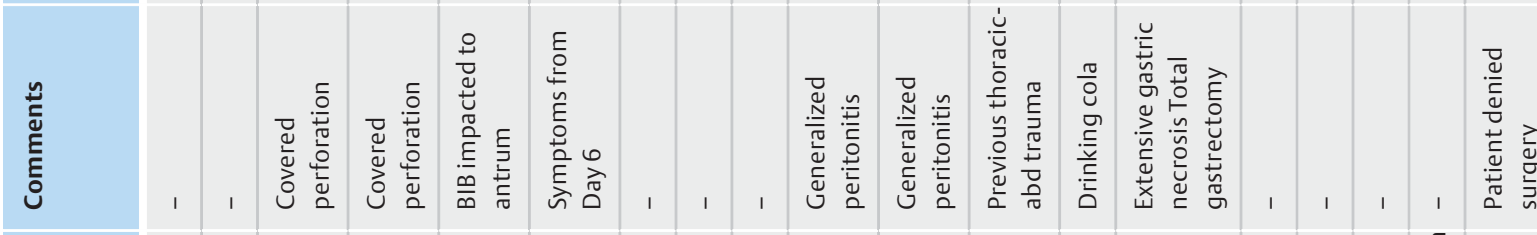
II

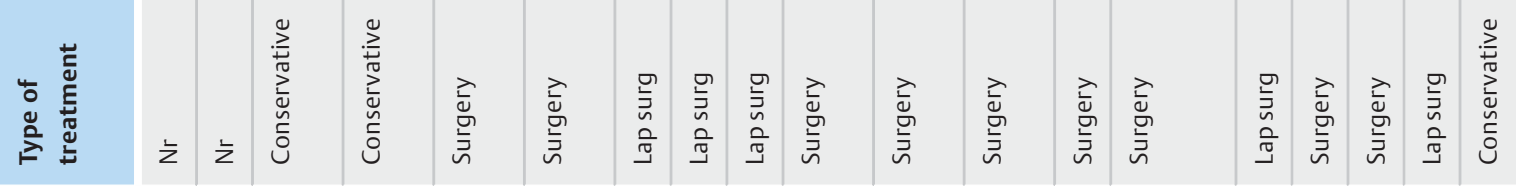

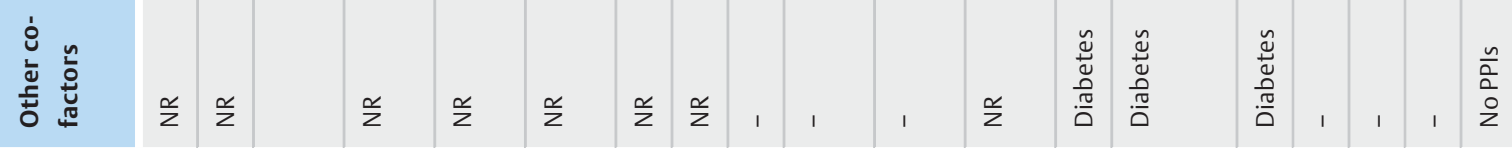
望望

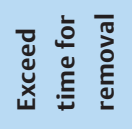
II

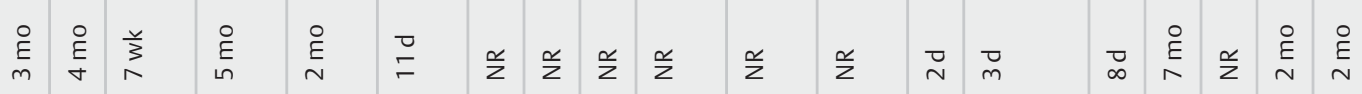

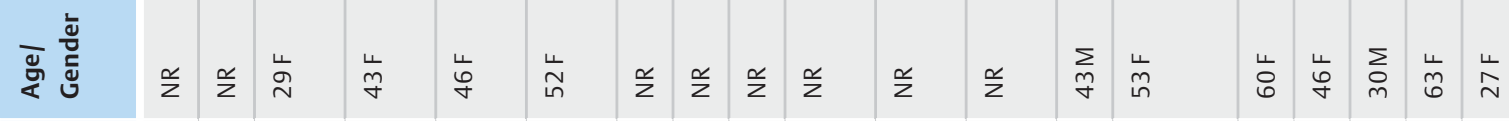

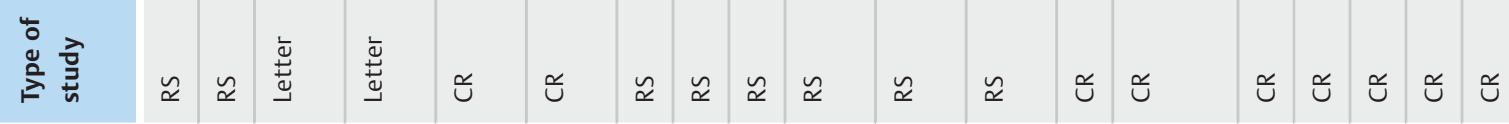
苞言

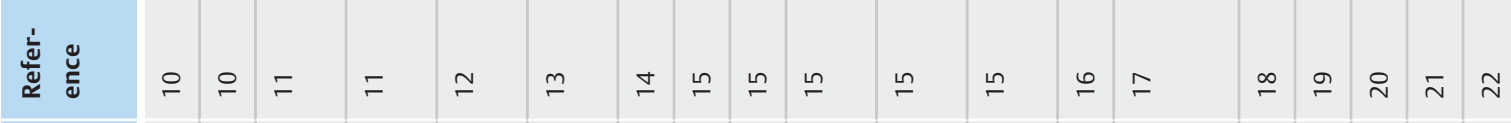

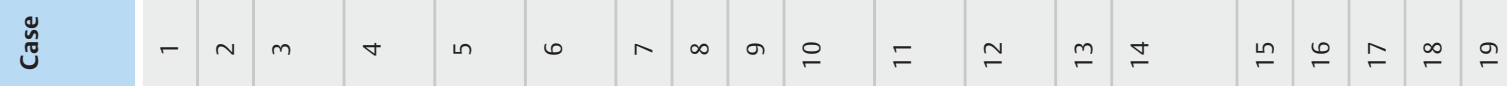




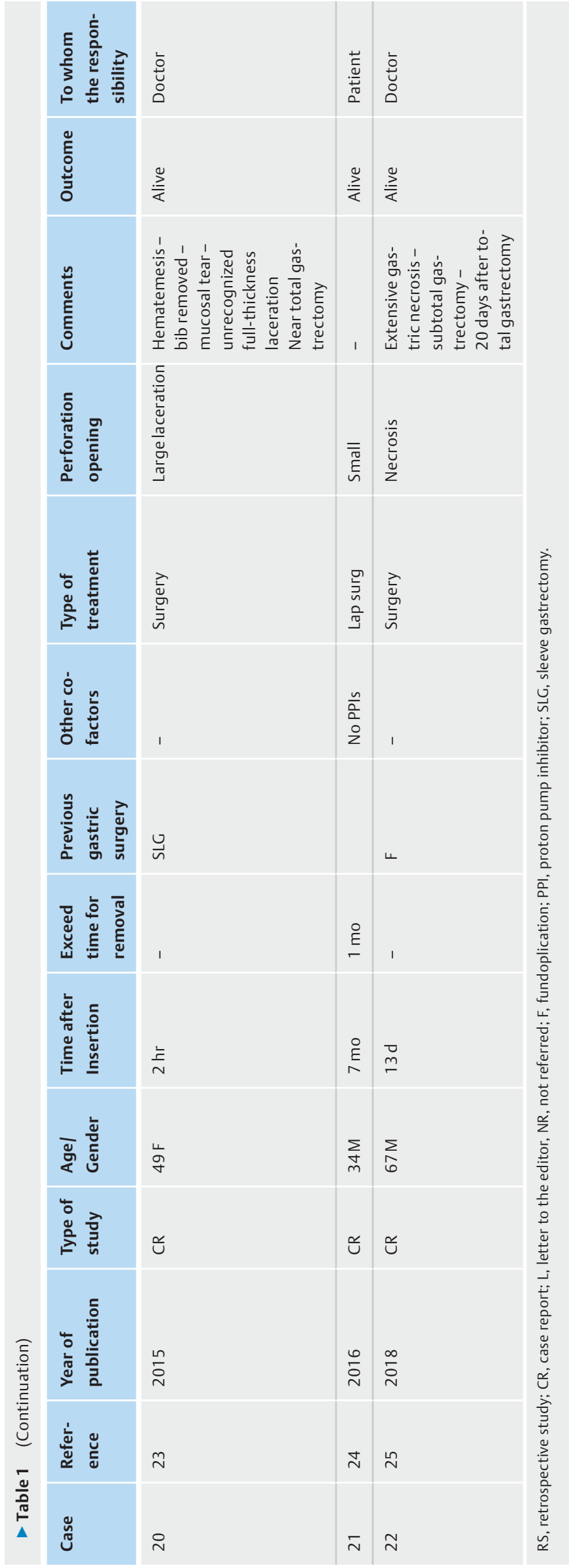

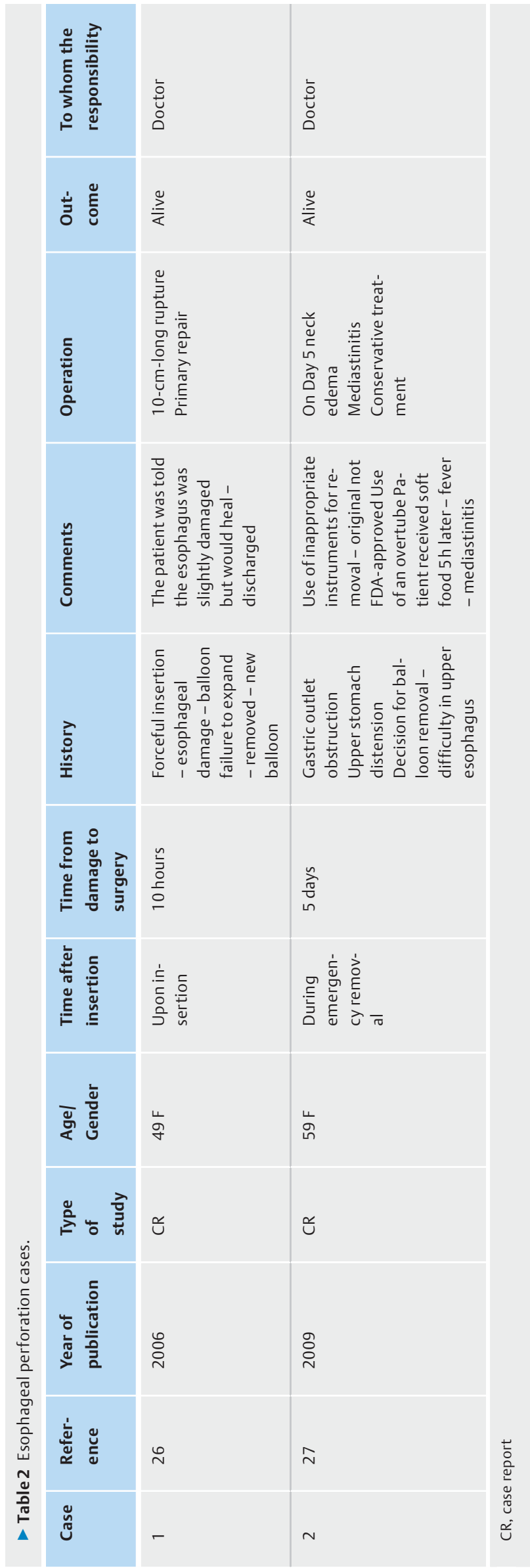




\begin{tabular}{|c|c|c|c|c|c|c|c|c|c|c|c|}
\hline 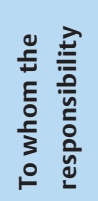 & 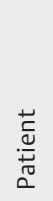 & 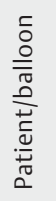 & 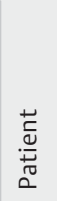 & 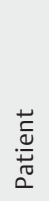 & 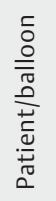 & 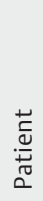 & 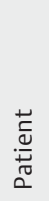 & 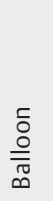 & 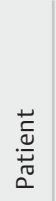 & 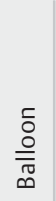 & 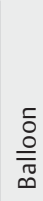 \\
\hline 守 气̆ & $\stackrel{\grave{z}}{\bar{\alpha}}$ & 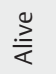 & $\stackrel{0}{\stackrel{\Sigma}{\leftarrow}}$ & $\stackrel{\stackrel{2}{z}}{\frac{\pi}{\alpha}}$ & $\stackrel{\Perp}{\stackrel{2}{\alpha}}$ & $\stackrel{\stackrel{2}{z}}{\alpha}$ & $\stackrel{\stackrel{2}{z}}{\frac{\partial}{4}}$ & 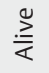 & $\stackrel{\text { }}{\stackrel{一}{<}}$ & $\stackrel{\check{z}}{\stackrel{一}{<}}$ & $\stackrel{\stackrel{2}{z}}{\frac{2}{4}}$ \\
\hline
\end{tabular}

\begin{tabular}{|c|c|c|c|c|c|c|}
\hline & 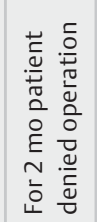 & 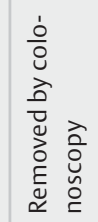 & 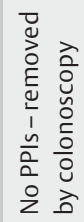 & 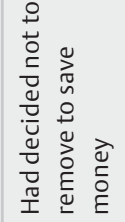 & 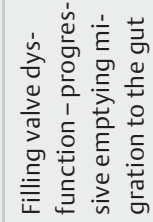 & 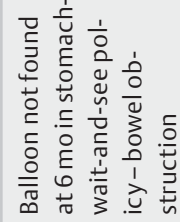 \\
\hline
\end{tabular}

\begin{tabular}{|c|c|c|c|c|c|c|c|c|c|c|c|}
\hline 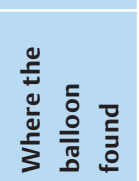 & $\begin{array}{l}\frac{\overline{0}}{\overline{0}} \\
\bar{E} \\
\overline{\tilde{n}}\end{array}$ & 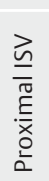 & $\begin{array}{l}\frac{\overline{0}}{0} \\
\frac{\dot{t}}{\dot{亠}} \\
\end{array}$ & 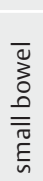 & $\underline{\Xi}$ & 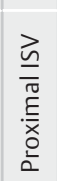 & $\underline{\Xi}$ & 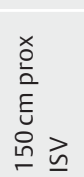 & 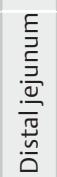 & $\frac{a}{z}$ & 呫 \\
\hline
\end{tabular}

\begin{tabular}{|c|c|c|c|c|c|c|c|c|c|c|c|}
\hline 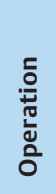 & $\begin{array}{l}\overrightarrow{\mathrm{E}} \\
\frac{\mathrm{0}}{0} \\
\frac{0}{0}\end{array}$ & 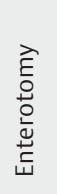 & 1 & 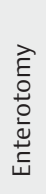 & 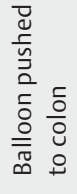 & 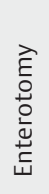 & 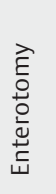 & 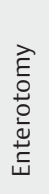 & 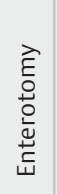 & $\frac{a}{z}$ & $\frac{a}{z}$ \\
\hline
\end{tabular}

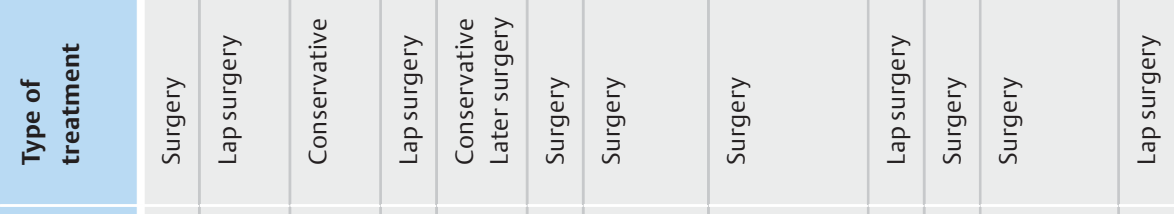

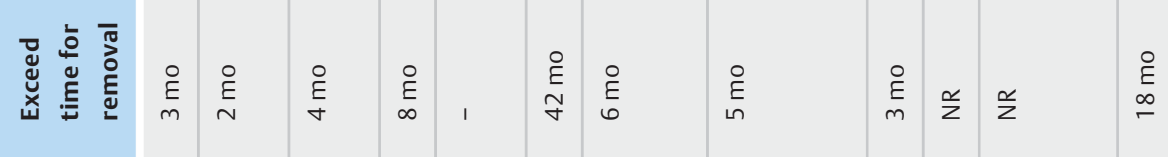

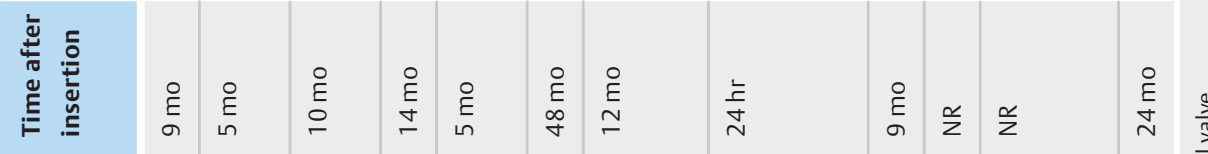

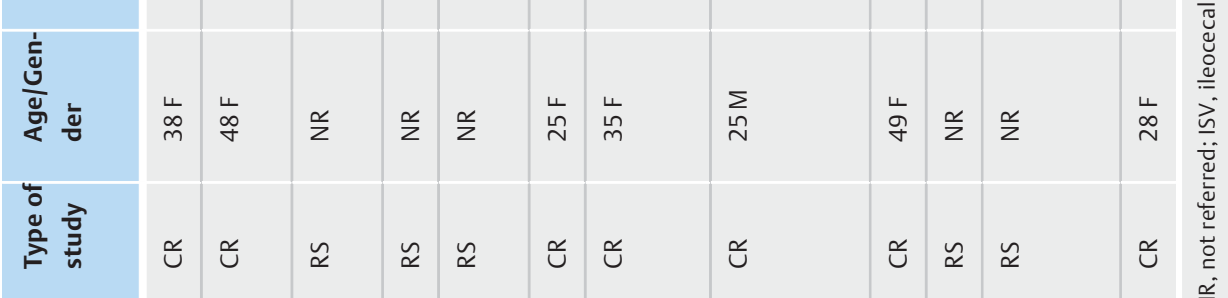

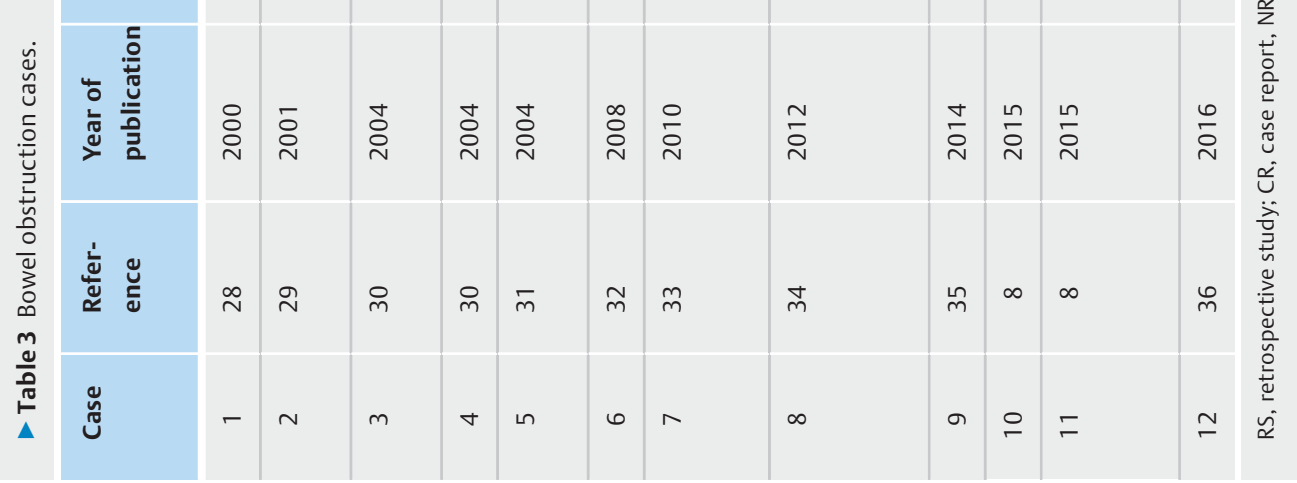


perforation and bowel obstruction. Our knowledge regarding the incidence of such complications is mainly based on individual cases, published as case reports by the treating surgeon, and also on published retrospective clinical studies by the endoscopists who placed the balloons; in such cases, complications are referred to without details.

The relatively recent FDA approval for use of the Orbera IGB in the United States has led to increased reports of deaths in obese individuals with a balloon in their stomach, without the implication of the balloon's involvement having been proven [39]. These reports, as well as the related, unreasonable request [9] for FDA approval recall, led us to the decision to investigate reports in the literature of severe complications affecting hollow viscera, namely gastric and esophageal perforations and bowel obstruction; where and how the balloon was implanted, the time it remained in the stomach, and its removal procedure. For two clearly technical reasons, we focused on only BIB/Orbera balloons. The Orbera is the balloon in longest use and theoretically, with which the most complications occurred and we wanted to study balloons with exactly the same external characteristics.

Gastric perforation was the most frequently described complication among the three complications studied: 22 cases. Nine of these 22 cases (40.9\%) occurred very early after implantation ( 2 hours up to 3 days) in patients having a relative contraindication for balloon insertion, i.e. previous gastric or bariatric surgery, which obviously modifies stomach compliance [23]. These were seven patients who previously had been subjected to fundoplication for hernia repair (two of whom finally died) $[13,15,17,25]$, one who had undergone sleeve gastrectomy [23] and one with a history of severe abdominal and thoracic trauma [15]. An over-optimistic but rather inexperienced physician seems to have been "responsible" for the huge perforations of the gastric wall, which is mainly attributable to extended tissue ischemia, since an intact gastric wall is initially considered a crucial prerequisite for balloon placement. However, if an experienced physician had been involved in the balloon insertions in these cases, gastric wall perforation might have been avoided.

We had previously reported that the main criteria for balloon placement in an operated stomach are the volume of the residual stomach and the principle that wall tension must be avoided-the stomach not stretched, just filled [40]. And, even more, that insertion of an IGB should not be considered a simple endoscopic procedure to be carried out by an inexperienced endoscopist. This seems to be a crucial point. Individual doctors or even institutions without experience, accreditation or the ability to resolve obesity-related or bariatric surgery-related complications $[38,41]$ must not undertake such procedures. Apollo manufacturers in the United States, since FDA approval, report about 5000 balloons sold between July 2015 and August 2017 [42]; the American Society for Metabolic and Bariatric Surgery reports 5744 balloons had been inserted in 2016, while facilities accredited to perform the procedure have placed only 1003 of the devices [43]. Who has placed the other 4741 devices in the United States?
Two obese individuals suffered a gastric wall perforation for a balloon implanted at least 7 months earlier, according to the patients' statements $[19,24]$; one claimed to have been given no conclusion date for removal and the other said that she could keep it for 2 years. In those two cases, we can attribute responsibility to the patient. One of these two, as well as another patient in our study, were also responsible for their complication because they were not taking the PPIs [22, 24] In addition, one more individual is to blame due to excess consumption of cola (instead of following the given instructions for the specific liquid diet) upon balloon implantation, leading to a large linear perforation in the gastric fundus and death 2 days later [16].

Finally, gastric perforation that occurred in the remaining nine cases could easily be attributed to excessive constant pressure exerted from continuous contact of the balloon itself, or its filling valve, on the gastric wall, with subsequent ischemia, erosion, maybe ulcer formation and eventual perforation [10-12, $14,18,20,21]$ which would finally be fatal. There is no information about the exact cause of perforation; we assume specific circumstances, such as when balloon mobility is restricted due to impingement with the gastric wall [12] assisted by presence of diabetes and/or failure to take PPIs.

Such cases of balloon-induced perforations are neither associated with the longevity of device within the stomach nor to development of an ulcer nor otherwise; thus, there are perforations occurring as early as 8 days after placement [18] and as late as 7 months $[19,24]$ and both small perforations (measured in $\mathrm{mm}$ ) and extended lacerations of the gastric wall. However, a small part of the responsibility also can be attributed to the patient with persisting symptoms not reported to his attended physician (if any) but also to the standard operation of the medical services. When a "balloon" patient comes to an emergency department complaining of severe abdominal pain, gastric perforation needs to be ruled out. Should the suspicion arise, the patient should not be allowed to leave without a computed tomography scan [44], and this makes the difference: An experienced endoscopist and surgeon will always consider the worst scenario, and so, will early recognize the signs of perforation.

Regarding complications related to the esophagus, there are fortunately only two cases in the literature: one during balloon positioning leading to a cranio-caudal esophageal rupture measuring at least $10 \mathrm{~cm}$ [26] and another one during urgent balloon removal [27] by a rather inexperienced medical group. In the latter case, the medical group also did not have the proper instruments for removal because they were not yet FDA-approved in the United States. These severe complications, which could very easily have become fatal, are mainly attributed to the physicians. In the first case, they are reported as experienced; however, although they noted the development of an esophageal damage, the physicians did not exhibit the appropriate awareness and allowed the patient to leave; in the second case, the patient presented with signs of epigastric pain, nausea and vomiting after a mechanical gastric outlet obstruction due to an intragastric balloon. The medical stuff decided to remove the balloon endoscopically, although they probably had 
never performed such an extraction in the past (even uncomplicated), because they had no proper endoscopic devices to do so.

Finally, there are 12 reported cases of bowel obstruction [ 8 , 28-36] due to IGB deflation or partial deflation. All but five cases could be attributed to negligence of the patients in getting the balloon removed, after a median of 10 months (range 9 to 48 months) post-insertion [ $28,30,32,33,35,36]$. It is clearly evidence that there is a noticeable number of patients who consciously have postponed balloon removal for financial reasons. However, extending the length of balloon implantation beyond that recommended could lead to increased risk of deflation, due to changes in the mechanical properties of the material. Mechanical friction and chemical degradation from gastric acid may break it down, the PPIs acting prophylactically. However, there are five more reported cases: two balloons gave signs of deflation at 5 months [29,31], best attributed to filling valve dysfunction; one was removed by a combined laparoscopic and endoscopic/coloscopic approach [31], the second patient refused intervention and finally was operated on as an emergency 2 months later [29].The third balloon gave signs of filling valve dysfunction from placement, and the patient was finally operated on for bowel obstruction in the fifth month [34]. Two other balloons were not found in the stomach at 6month endoscopy for removal; a wait-and-see policy failed and the patients were operated on for bowel obstruction [8].

It is interesting to refer to a very old study (1998-2001) [30] in which the authors analyzed their early experience on 176 obese patients being subjected to balloon treatment. They reported that 49 of 176 balloons (27.8\%) unexpectedly evacuated spontaneously, during vomiting in four patients and in the stools in 45 , all cases but two occurring after the theoretical date of the 6-month lifespan of the balloon. Nobody wants to blame the authors in these very early days! But a rate as high as $27.8 \%$ for spontaneous evacuation, which theoretically could lead to bowel obstruction, should raise questions about such a delay: 49 of 176 patients had their balloons left implanted beyond the instructed 6-month period. Were they all counseled to proceed with removal but refused or were the patients not followed while they attempted to lose their excess weight?

Nowadays, according to Apollo Endosurgery reports [42], more than 277,000 balloons have been implanted worldwide, mainly in Brazil, Mexico, and Europe - fewer in Asia. In terms of numbers only, the percentages of serious complications reported are almost nil [4]. But there are human lives behind the numbers, and by our analysis, almost half of the complications could have been avoided, if the patients had been more compliant with instructions and some physicians better educated and accredited.

The American Society of Gastrointestinal Endoscopy's latest published directives state "...training and skill acquisition with endoscopic bariatric techniques and technologies is mandatory before clinical application is undertaken, and should include didactic as well as hands-on practical education". And, furthermore, "...importantly, any practitioner who is interested in performing an endoscopic bariatric procedure should also be educated in the clinical management of obese patients," that means, have the ability to resolve complications themselves [6].

\section{Conclusion}

In conclusion, the BIB/Orbera balloon treatment seems to remain a safe procedure, with a minimum of complications related to hollow viscera, some of which could be avoided. Mandatory education and accreditation of physicians dealing with bariatric endoscopy and strict supervision of obese individuals throughout the time they have the balloon in their stomachs will eliminate most such complications. Successful weight loss by means of the balloon essentially depends on the skill and attention of the doctor, the consistent, active and informed participation of the patient, and the high quality of the balloon itself.

\section{Competing interests}

\section{None}

\section{References}

[1] Gleysteen JJ. A history of intragastric balloons. Surg Obes Relat Dis 2016; $12: 430-435$

[2] Genco A, López-Nava G, Wahlen C et al. Multi-centre European experience with intragastric balloon in overweight populations: 13 years of experience. Obes Surg 2013; 23: 515-521

[3] Kotzampassi K, Grosomanidis V, Papakostas P et al. 500 intragastric balloons: what happens 5 years thereafter? Obes Surg 2012; 22: $896-903$

[4] Imaz I, Martinez-Cervell C, Garcia-Alvarez EE et al. Safety and effectiveness of the intragastric balloon for obesity. A meta-analysis. Obes Surg 2008; 18: $841-846$

[5] Kotzampassi K, Shrewsbury AD, Papakostas P et al. Looking into the profile of those who succeed in losing weight with an intragastric balloon. J Laparoendosc Adv Surg Tech A 2014; 24: 295 - 301

[6] Abu Dayyeh BK, Kumar N, Edmundowicz SA et al. ASGE Bariatric Endoscopy Task Force and ASGE Technology Committee. ASGE Bariatric Endoscopy Task Force systematic review and meta-analysis assessing the ASGE PIVI thresholds for adopting endoscopic bariatric therapies. Gastrointest Endos 2015; 82: 425-438

[7] Laing P, Pham T, Taylor L] et al. Filling the Void: A Review of Intragastric Balloons for Obesity. Dig Dis Sci 2017; 62: 1399-1408

[8] Mathus-Vliegen EM, Alders PR, Chuttani R et al. Outcomes of intragastric balloon placements in a private practice setting. Endoscopy 2015; 47: $302-307$

[9] Tate CM, Geliebter A. Intragastric Balloon Treatment for Obesity: FDA Safety Updates. Adv Ther 2018; 35: 1-4

[10] Totté E, Hendrickx L, Pauwels M et al. Weight reduction by means of intragastric device: experience with the bioenterics intragastric balloon. Obes Surg 2001; 11: 519-523

[11] Bataille L, Descamps C, Miroult L. Covered gastric perforation by the BioEnterics Intragastric Balloon. J Clin Gastroenterol 2001; 33: 344 345

[12] Roche-Nagle G, Mulligan E, Connolly E et al. Unusual cause of a perforated stomach. Ann R Coll Surg Engl 2003; 85: 396 - 397 
[13] Giardiello C, Cristiano S, Cerbone MR et al. Gastric perforation in an obese patient with an intragastric balloon, following previous fundoplication. Obes Surg 2003; 13: 658-660

[14] Al-Momen A, El-Mogy I. Intragastric balloon for obesity: a retrospective evaluation of tolerance and efficacy. Obes Surg 2005; 15: 101 105

[15] Genco A, Bruni T, Doldi SB et al. BioEnterics Intragastric Balloon: The Italian Experience with 2,515 Patients. Obes Surg 2005; 15: 1161 1164

[16] Koutelidakis I, Dragoumis D, Papaziogas B et al. Gastric perforation and death after the insertion of an intragastric balloon. Obes Surg 2009; 19: $393-396$

[17] Rodríguez-Hermosa Jl, Roig-García J, Gironès-Vilà J et al. Gastric necrosis: a possible complication of the use of the intragastric balloon in a patient previously submitted to Nissen fundoplication. Obes Surg 2009; 19: $1456-1459$

[18] Smigielski JA, Szewczyk T, Modzelewski B et al. Gastric perforation as a complication after BioEnterics intragastric balloon bariatric treatment in obese patients-synergy of endoscopy and videosurgery. Obes Surg 2010; 20: $1597-1599$

[19] Knoetze R, van Mollendorff V, Wan YO. Gastric perforation as a complication of an intragastric balloon. Continuing Medical Education 2010; 28: 392

[20] Ramia Angel JM, de la Plaza Llamas R, Veguillas Redondo P et al. Stomach perforation in a patient with an intragastric balloon. Cir Esp 2010; 87: 397-399 [Article in Spanish]

[21] Charalambous MP, Thompson J, Efthimiou E. Late gastric perforation after insertion of intragastric balloon for weight loss-video case report and literature review. Surg Obes Relat Dis 2012; 8: 121-123

[22] Bekheit M, Abdelsalam WN, Sgromo B et al. Is conservative management for gastric perforation secondary to intragastric balloon possible? Case report and review of literature Obes Surg 2014; 24: 968 970

[23] El Hage Chehade HH, El Khatib ZO, Abtar HK. What could happen if you insert a BioEnterics intragastric balloon after sleeve gastrectomy? Surg Obes Relat Dis 2015; 11: e39-e41

[24] Abou Hussein BM, Khammas AA, Al Ani AM et al. Gastric perforation following intragastric balloon insertion: combined endoscopic and laparoscopic approach for management: case series and review of literature. Obes Surg 2016; 26: 1127-1132

[25] Ríos A, Febrero B, Rodríguez JM. Gastric perforation by intragastric balloon in patient with Nissen fundoplication. Gastroenterol Hepatol 2018; 41: 251-253

[26] Nijhof HW, Steenvoorde P, Tollenaar RA. Perforation of the esophagus caused by the insertion of an intragastric balloon for the treatment of obesity. Obes Surg 2006; 16: 667-670

[27] Ruiz D, Vranas K, Robinson DA et al. Esophageal perforation after gastric balloon extraction. Obes Surg 2009; 19: 257-260
[28] Kim WY, Kirkpatrick U], Moody AP et al. Large bowel impaction by the BioEnterics Intragastric Balloon (BIB) necessitating surgical intervention. Ann R Coll Surg Engl 2000; 82: 202 - 204

[29] Vanden Eynden F, Urbain P. Small intestine gastric balloon impaction treated by laparoscopic surgery. Obes Surg 2001; 11: 646-648

[30] Roman S, Napoléon B, Mion F et al. Intragastric balloon for "nonmorbid" obesity: a retrospective evaluation of tolerance and efficacy. Obes Surg 2004; 14: 539-544

[31] Sallet JA, Marchesini JB, Paiva DS et al. Brazilian multicenter study of the intragastric balloon. Obes Surg 2004; 14: 991 - 998

[32] Alnafisi BA. Small bowel obstruction caused by delayed intragastric balloon impaction. Radiol Case Rep 2015; 3: 176

[33] Zdichavsky M, Beckert S, Kueper M et al. Mechanical ileus induces surgical intervention due to gastric balloon: a case report and review of the literature. Obes Surg 2010; 20: 1743-1746

[34] Mousavi Naeini SM, Sheikh M. Bowel obstruction due to migration of an intragastric balloon necessitating surgical removal before completion of the recommended 6 months. Case Rep Med 2012; 2012: 414095

[35] Di Saverio S, Bianchini Massoni C, Boschi S et al. Complete smallbowel obstruction from a migrated intra-gastric balloon: emergency laparoscopy for retrieval via enterotomy and intra-corporeal repair. Obes Surg 2014; 24: $1830-1832$

[36] Al Shammari NM, Alshammari AS, Alkandari MA et al. Migration of an intragastric balloon: A case report. Int J Surg Case Rep 2016; 27: 10 12

[37] Schapiro M, Benjamin S, Blackburn G et al. Obesity and the gastric balloon: a comprehensive workshop. Tarpon Springs, Florida, March 19-21, 1987. Gastrointest Endosc 1987; 33: 323-327

[38] Runkel N, Colombo-Benkmann M, Hüttl TP et al. Evidence-based German guidelines for surgery for obesity. Int J Colorectal Dis 2011; 26: $397-404$

[39] Voelker R. Deaths reported after intragastric balloon surgery. JAMA 2017; 318: 996

[40] Kotzampassi K, Eleftheriadis E. Not stretch, just fill. Surg Obes Relat Dis 2016; 12: 725

[41] ORBERA Intragastric Balloon System. Apollo Endosurgery. Directions for Use. At: www.accessdata.fda.gov/cdrh_docs/pdf14/P140008c. pdf [Last accessed September 10th 2018]

[42] https://apolloendo.com/orbera Last accessed September 10th 2018

[43] English WJ, DeMaria EJ, Brethauer SA et al. American Society for Metabolic and Bariatric Surgery estimation of metabolic and bariatric procedures performed in the United States in 2016. Surg Obes Relat Dis 2018; 14: $259-263$

[44] Brooks ]. Intragastric balloon-induced ischemic perforation. Obes Surg 2016; 26: $161-162$ 